\title{
Screen Channel Liquid Acquisition Device Outflow Tests in Liquid Hydrogen
}

\author{
J.W. Hartwig ${ }^{1}$, D.J. Chato ${ }^{1}$, J.B. McQuillen ${ }^{2}$, J. Vera ${ }^{3}$, M.T. Kudlac ${ }^{3}$, and F.D. Quinn ${ }^{3}$ \\ ${ }^{1}$ Propulsion and Propellants Branch, Glenn Research Center \\ ${ }^{2}$ Fluid Physics and Transport Branch, Glenn Research Center \\ ${ }^{3}$ Fluids Systems and Engineering Branch, Glenn Research Center \\ Corresponding author: Jason W. Hartwig \\ M/S: 301/3 \\ NASA Glenn Research Center, Cleveland, OH 44135 \\ Jason.W.Hartwig@nasa.gov \\ PH: 216-368-3979
}

\begin{abstract}
This paper presents experimental design and test results of the recently concluded 1-g inverted vertical outflow testing of two $325 \times 2300$ full scale liquid acquisition device (LAD) channels in liquid hydrogen $\left(\mathrm{LH}_{2}\right)$. One of the channels had a perforated plate and internal cooling from a thermodynamic vent system (TVS) to enhance performance. The LADs were mounted in a tank to simulate 1-g outflow over a wide range of $\mathrm{LH}_{2}$ temperatures $(20.3-24.2 \mathrm{~K})$, pressures $(100-$ $350 \mathrm{kPa})$, and flow rates $(0.010-0.055 \mathrm{~kg} / \mathrm{s})$. Results indicate that the breakdown point is dominated by liquid temperature, with a second order dependence on mass flow rate through the LAD. The best performance is always achieved in the coldest liquid states for both channels, consistent with bubble point theory. Higher flow rates cause the standard channel to break down relatively earlier than the TVS cooled channel. Both the internal TVS heat exchanger and subcooling the liquid in the propellant tank are shown to significantly improve LAD performance.
\end{abstract}

\subsection{Keywords}

Liquid acquisition devices, liquid hydrogen, cryogenic fluid management, subcooled liquid, thermodynamic vent heat exchanger, fuel depot

\subsection{Nomenclature}

$C_{\min } \quad$ Minimum heat capacity rate of the hot and cold fluids $(\mathrm{W} / \mathrm{K})$

$c_{p, L A D} \quad$ Specific heat of liquid inside LAD channel $(\mathrm{J} / \mathrm{kgK})$

$D_{p} \quad$ Screen pore diameter $(\mu \mathrm{m})$

$\varepsilon \quad$ Efficiency of TVS heat exchanger

$F \quad$ Two phase multiplier

$h_{i} \quad$ Heat transfer coefficient of cold TVS fluid $\left(\mathrm{W} / \mathrm{m}^{2} \mathrm{~K}\right)$

$h_{L} \quad$ Heat transfer coefficient assuming all liquid flow $\left(\mathrm{W} / \mathrm{m}^{2} \mathrm{~K}\right)$

$h_{N B} \quad$ Heat transfer coefficient for nucleate boiling $\left(\mathrm{W} / \mathrm{m}^{2} \mathrm{~K}\right)$

$\dot{m}_{L A D} \quad$ Outflow rate through the LAD channel $(\mathrm{kg} / \mathrm{s})$ 


$\begin{array}{ll}N T U & \text { Number of heat transfer units } \\ P & \text { Tank pressure (kPa) } \\ P_{S A T} & \text { Saturation pressure based on the temperature of the liquid at the screen (kPa) } \\ \dot{Q} & \text { Heat transfer rate between cold TVS fluid and warm LAD fluid (W) } \\ S & \text { Nucleate boiling suppression factor } \\ T_{h, \text { in }} & \text { Temperature of incoming liquid into LAD channel (K) } \\ T_{h, \text { out }} & \text { Temperature of the outgoing liquid out of the top of the LAD channel (K) } \\ \Delta P_{B P} & \text { Bubble point pressure (Pa) } \\ \Delta P_{B P, N B P} & \text { Bubble point pressure at normally saturated conditions (Pa) } \\ \Delta P_{\text {dynamic }} & \text { Dynamic pressure loss inside LAD channel (Pa) } \\ \Delta P_{F T S} & \text { Flow through screen pressure drop (Pa) } \\ \Delta P_{\text {frictional }} & \text { Frictional pressure loss inside LAD channel (Pa) } \\ \Delta P_{\text {hydrostatic }} & \text { Hydrostatic pressure drop (Pa) } \\ \Delta P_{\text {other }} & \text { Transient pressure drop terms }(\mathrm{Pa}) \\ \Delta P_{\text {total }} & \text { Total pressure loss for LAD system }(\mathrm{Pa}) \\ \varepsilon & \text { Heat exchanger effectiveness } \\ \gamma & \text { Surface tension (mN/m) } \\ \theta_{C} & \text { Contact angle }\end{array}$

\subsection{Introduction}

The enabling of all future in-space cryogenic engines and cryogenic fuel depots for long duration human and robotic space exploration missions begins with technology development of cryogenic fluid management (CFM) systems upstream in the propellant tank. Depending on the mission requirements, which include acceleration level, direction, and spin, mass flow rate, thermal environment, tank pressure, and desired expulsion efficiency, multiple CFM technologies will be required to ensure efficient long term storage and transfer of cryogenic propellants. There are two primary customers or applications for CFM technology. In-space cryogenic engines will require vapor free propellant transfer over a wide range of flow rates in milli- and microgravity environments over a wide range of thermal environments. Future in-space cryogenic fuel depots, which are of particular interest in the current work, will also require efficient methods to store (in excess of one year) and transfer liquid hydrogen $\left(\mathrm{LH}_{2}\right)$ and liquid oxygen (LOX) from a depot storage tank to a customer receiver tank due to the projected overwhelming cost to launch and store propellant in Low Earth Orbit (LEO).

\subsection{Background}

Gravity affects many fluidic processes, such as the separation of liquid and vapor phases within a propellant tank. In Earth's standard 1-g environment, density of the fluid dictates the location of the vapor and liquid phases because the heavier liquid settles to the bottom and the lighter vapor rises to the top. In microgravity however, surface tension becomes the controlling mechanism because the liquid tends to adhere to the tank walls, leaving a gaseous core in the center of the tank. In-space transfer of cryogenic propellants begins with extraction of vapor free liquid from the storage tank. In normal gravity, liquid is easily removed from the bottom of the tank. In the 
reduced gravity of space however, liquid may not sufficiently cover the tank outlet, and so a variety of propellant management devices (PMDs) or liquid acquisition devices (LADs) may be required to favorably position liquid and ullage within the tank.

\subsection{Propellant Management Devices}

The primary purpose of a PMD is to transfer vapor free liquid from a propellant tank to a transfer line en route to an engine or receiver tank. The secondary purpose of a PMD is to feed a mixing pump inside a storage tank in order to de-stratify the liquid and provide adequate mixing and pressure control of the bulk propellant. All PMDs rely on surface tension forces and capillary flow to maintain communication between liquid, PMD, and tank outlet. PMDs must be specifically designed for each mission.

PMDs are broken down into three types, namely screen channel gallery arms, vanes, and sponges [1 - 3]. Screen channel LADs are designed and manufactured in a variety of styles, sizes, and geometries. As shown in Figure 1, gallery arms tend to closely follow the contour of the propellant tank wall and can have different cross section geometries (typically a triangular or rectangular shape) [1]. The channel side that faces the wall has openings covered with a tightly woven fine mesh screen. The screen has micron sized pores which are used to wick liquid into the channel, prevent pores from drying out during tank drain, and also act as a barrier to vapor ingestion. As liquid is withdrawn from the tank and vapor approaches the screen, surface tension forces at the screen generate a localized area of

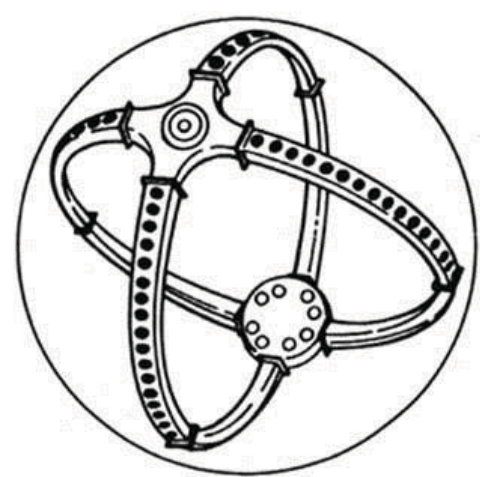

Figure 1: Full Communication Screen Channel Gallery Arm high pressure differential that blocks vapor entrance into the channel, but allow the liquid to flow freely. Liquid is wicked along the screen and prevents the pores from drying out if they come into contact with vapor. Full communication screen channel LADs (i.e. LADs that extend the entire length of the tank wall to maintain communication with the liquid at all time) have demonstrated flight heritage in storable propulsion (fluids that exist as liquids at room temperature) systems such as the STS Reaction Control System (RCS) and Orbital Maneuvering System (OMS) [4, 5], and the design of LADs for storables is well understood [6, 7]. Although screen channel LADs have been used in a small scale liquid helium experiment in microgravity [8], they have not been used with $\mathrm{LH}_{2}$ in low gravity. Screen channel LADs are the recommended technology approach for the future cryogenic depots due to a rich technology development program, flight heritage in storable propellants, and higher performance, flexibility, and robustness relative to vanes and sponges [9].

\subsection{Screen Channel Liquid Acquisition Devices}

For flight systems, screen channel LAD usage is broken into two categories [10, 11]. Start baskets, traps, and start tanks are considered small liquid acquisition devices that confine sufficient liquid to start engines until the relatively large accelerations can

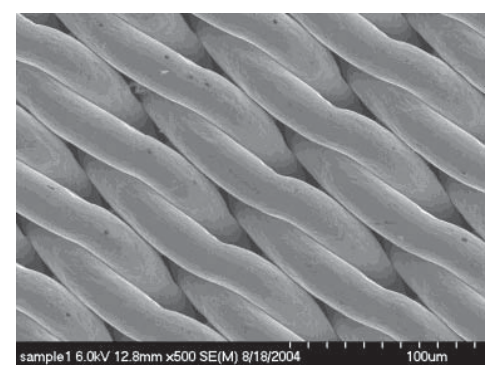

Figure 2: Scanning Electron Microscope Image of a $325 \times 2300$ Screen Sample 
adequately reorient the liquid for the large flow rates required for continuous engine operation. Meanwhile full communication channels, distributers, or tank liners are used in systems with small accelerations and small flows rates. Start baskets are used in systems that experience high flow rate demands over small time scales in milli- to microgravity while full communication gallery arms are implemented in systems with smaller flow rate demands over longer time scales in microgravity.

The choice of screen for the LAD is dictated by the gravitational environment and desired maximum flow rate, which can be estimated through knowledge of the bubble point pressure. Screens are characterized by the screen weave, which refers to the number of wires per inch in each direction, and the specific weave pattern used during manufacturing. For example, the $325 \times 2300$ Dutch Twill mesh screen displayed in Figure 2 has 325 warp wires and 2300 shute wires per square inch of the screen. For a Dutch Twill, each shute wire passes under two warp wires before traveling over the next two warp wires. Fine mesh Dutch Twill screens create very small pores and provide a tortuous path and good resistance against gas ingestion, and provide more margin in system design, which make them popular candidates for low surface tension cryogenic liquids. However, they may generate large hydraulic pressure losses during outflow and may become clogged by particulate matter.

\subsection{The Bubble Point}

The primary performance parameter characterizing LADs is the bubble point, which is defined as the differential pressure required to overcome the liquid surface tension force at the screen pore. Physical parameters that affect the bubble point include the geometry and size of the screen pore and surface tension of the liquid in contact with the screen:

$\Delta P_{B P}=\frac{4 \gamma \cos \theta_{C}}{D_{P}}$

where $\gamma$ is the surface tension of the fluid, $\theta_{C}$ is the contact angle between liquid propellant and solid screen pore, and $D_{P}$ is the effective pore diameter [12]. To prevent vapor ingestion into the channel during outflow, the total pressure loss in the LAD system must be less than the bubble point pressure:

$\Delta P_{\text {total }}<\Delta P_{B P}$

where the total pressure loss is expressed as:

$\Delta P_{\text {total }}=\Delta P_{\text {hydrostatic }}+\Delta P_{F T S}+\Delta P_{\text {friction }}+\Delta P_{\text {dynamic }}+\Delta P_{\text {other }}$

where $\Delta P_{\text {hydrostatic }}$ is the hydrostatic pressure within the channel, $\Delta P_{F T S}$ is the pressure drop across the screen due to liquid flow, $\Delta P_{\text {friction }}$ is the frictional loss down the LAD channel, $\Delta P_{\text {dynamic }}$ is the dynamic pressure drop due to inflow into the channel, and $\Delta P_{\text {other }}$ is the pressure loss contribution due to vibrations, propellant sloshing, and/or transients [13]. The parameters that affect bubble point, including screen mesh type, liquid, liquid pressure and temperature (i.e. the amount of 
subcooling), pressurant gas type and pressurant gas temperature have been systematically investigated in four primary cryogenic liquids, including LH2 and liquid nitrogen $\left(\mathrm{LN}_{2}\right)[9,14-$ 16], LOX [17-19], and liquid methane $\left(\mathrm{LCH}_{4}\right)$ [20, 21], as well as room temperature liquids [12, 22,23 . Equations 1 and 3 can be used to predict the breakdown point of a screen channel LAD in any given gravitational and thermal environment.

\subsection{Test Purpose}

Before LADs can be considered a viable option for cryogenic liquid acquisition systems in microgravity, they must first be qualified in ground testing. The purpose of the current work was to design, characterize, and parametrically test two $325 \times 2300$ full scale LAD channels in $\mathrm{LH}_{2}$ in an inverted outflow configuration over a wide range of liquid temperatures $(20.3-24.2 \mathrm{~K})$, pressures $(100-350 \mathrm{kPa})$, and flow rates $(0.010-0.055 \mathrm{~kg} / \mathrm{s})$ representative of a depot propellant tank and transfer. Test results will influence the design and operating ranges of flight LADs for future cryogenic depots. Tests here will also be instrumental in determining the effectiveness and suitability of applying LAD channel designs to all future cryogenic fueled systems.

Table 1 summarizes the four architectures referenced to determine test conditions (maximum expected operating pressure, flow rate, and transfer line size and velocity). These include the two original Cryogenic Propellant Storage and Transfer Technology Demonstration Mission (CPST TDM) reference points [24], the proposed Centaur upper stage to the Cryogenic Orbital TestbedLITE (CRYOTE-LITE) transfer $[25,26]$, as well as estimated, scaled parameters for a full scale depot. Depot parameters are estimated based on a Martian surface/return mission.

\begin{tabular}{|c|c|c|c|c|c|}
\hline & & & Transfer Line & Transfer Line & Transfer Line \\
\hline & Reference Point & MEOP [kPa] & Flow Rate [kg/s] & ID (OD) [cm] & Velocity $[\mathrm{m} / \mathrm{s}]$ \\
\hline 1 & CPST Reference Point \#1 & $207-345$ & $0.01^{*}$ & $1.1[1.3]$ & $3.48-3.66$ \\
\hline 2 & CPST Reference Point \#2 & $207-345$ & $0.02 *$ & $1.1[1.3]$ & $6.64-6.99$ \\
\hline 3 & Centaur to CRYOTE-LITE & $207-276$ & 0.182 & $2.2[2.5]$ & $7.03-7.39$ \\
\hline \multirow[t]{4}{*}{4} & Full Scale Depot & $207-276$ & $2.73^{* *}$ & $5.8[7.6]$ & $15.08-15.87$ \\
\hline & Assumptions & & & & \\
\hline & *Pre-Phase A POD, 27, Jul & 2011 & & & \\
\hline & **Based off scaling, [27] & & & & \\
\hline
\end{tabular}

Table 1: Summary of Reference Missions

\subsection{Experimental Design and Methodology}

\subsection{5x2300 LAD Channel Design}

Two $91 \mathrm{~cm}$ long by $2.54 \mathrm{~cm}$ wide by $2.54 \mathrm{~cm}$ deep (36.2'” 1 '” x 1') LAD channels were built, a standard 325x2300 channel and a thermodynamic vent system (TVS) cooled 325x2300 channel. The width and depth of both channels were sized based off analysis of the pressure drop model from [13] to achieve a broad range of breakdown locations and also to maximize the FTS and frictional pressure losses. The 36" height was chosen to overcome the relatively large $\mathrm{LH}_{2}$ hydrostatic pressure drop over the range of liquid temperatures tested. 
A cutout of the standard and TVS cooled channels is shown in Figures 3 and 4, respectively. Channels were constructed in a piecewise fashion in the following procedure: 304 stainless steel (SS) $325 \times 2300$ LAD screens were first diffusion bonded to a frame. A "sandwich" approach was used to bond the

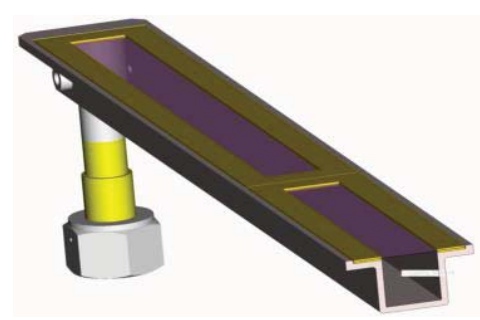

Figure 3: 325x2300 Standard Channel

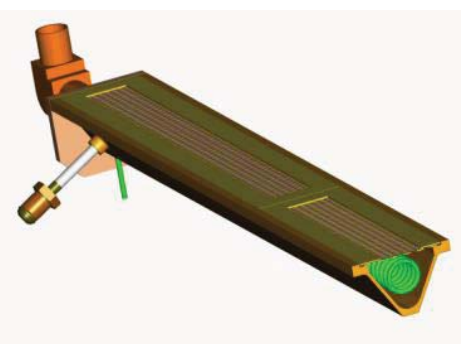

Figure 4: 325x2300 TVS Cooled Channel

screens between two SS plates. Bonding was performed in a vacuum furnace at $1422 \mathrm{~K}$ using hydraulic rams to apply the compressive forces to the mating plates to achieve the bond. To promote sealing of the screen at the edges, a thin bead of Nickel was deposited at the plate/screen interface. This was done to ensure breakdown did not occur at the screen edges where some of the screen pores could have been prematurely deformed due to the compressive forces. Scanning electron microscopy (SEM) imaging of the pieces indicated that the Ni coating was not wicked appreciably onto the screen away from the pores. Although it was desirable to fabricate a single 36 " screen piece, sample length was limited to approximately $29 \mathrm{~cm}(11.4$ "') due to the size of the furnace. To achieve the desired total length of screen area, three individual $2.54 \mathrm{~cm}(1.0$ ') wide by $29 \mathrm{~cm}$ (11.4') long samples were diffusion bonded to the backing plates with a $1.3 \mathrm{~cm}$ $(0.5$ ') frame all around as shown in Figure 3. This created a $2.54 \mathrm{~cm} \times 2.54 \mathrm{~cm}(1$ '” 1 '") flow path or hydraulic diameter inside the channel.

Second, each $325 \times 2300$ screen piece/backing plate was individually bubble point tested in isopropyl alcohol (IPA) for performance and acceptance testing. Third, the screen sample/backing plates were then welded on top of the channel as shown in Figures 3 and 4. The channel was fabricated with a liquid outflow port at the top of the channel and with instrumentation ports to measure two differential pressures: across the screen and from the bottom to top of the channel. A single silicon diode (SD) was epoxy bonded to the screen side facing internal to the channel in order to correlate breakdown height

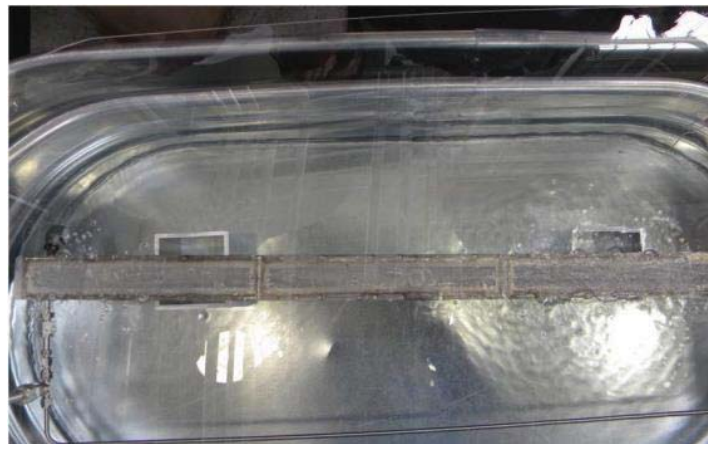

Figure 5: IPA Bubble Point Test of the $325 \times 2300$ Channel with predicted bubble point pressure based off this temperature as in all recent previously reported component level bubble point tests [e.g. 14, $19,21]$. Finally, after completed assembly, the channel was IPA bubble point tested for final acceptance. Figure 5 shows a picture of the IPA testing of the completed channel. Test results are reserved in Section 6.2. Detailed visual inspections of the screen/plate edge were also performed under a microscope for quality control.

\subsection{5x2300 TVS Cooled Channel Design}

\subsubsection{Screens and Channel}


The TVS cooled $325 \times 2300$ channel was fabricated in much the same way as the $325 \times 2300$ channel, but with a few differences. First, the individual screen samples had a perforated plate as the lower support plate as shown in Figure 4. The purpose of the plate was to provide additional structural support for the LAD screen, since launch loads may impose unwanted/unfavorable stresses on the screen. The plates cut down on the total area available for liquid flow to approximately $63 \%$ of the flow area of the standard $325 \times 2300$ channel. The LAD channel itself was triangular backed, as opposed to the straight back of the regular channel. As shown in Figure 4 , the purpose of the triangular backing was to allow room for an internal TVS heat exchanging coil while maintaining the same hydraulic diameter of the standard channel.

The purpose of the heat exchanger was to cool the liquid inside the channel, potentially lowering the surface tension of the liquid at the screen, and thus increase the duration of liquid outflow before gas ingestion. As indicated in Equation 1, lowering the liquid temperature inside the channel will increase bubble point pressure. To provide cooling of the liquid flow through the LAD, liquid from the bottom of the tank was routed through a Joule-Thompson (JT) device. Liquid expanded across the JT orifice at constant enthalpy, which caused a dramatic decrease in temperature. The liquid was then routed into the top of the LAD channel through a cooling coil, which acted as a counter flow heat exchanger for the liquid entering the channel through the LAD screen. Liquid was circulated through the cooling coil and then routed to a reduced vacuum environment $(<$ $14 \mathrm{kPa})$ to increase pressure drop and thus enhance performance of the JT orifice. The final assembled TVS cooled $325 \times 2300$ channel is shown in Figure 6.

\subsubsection{TVS Heat Exchanger Analysis}

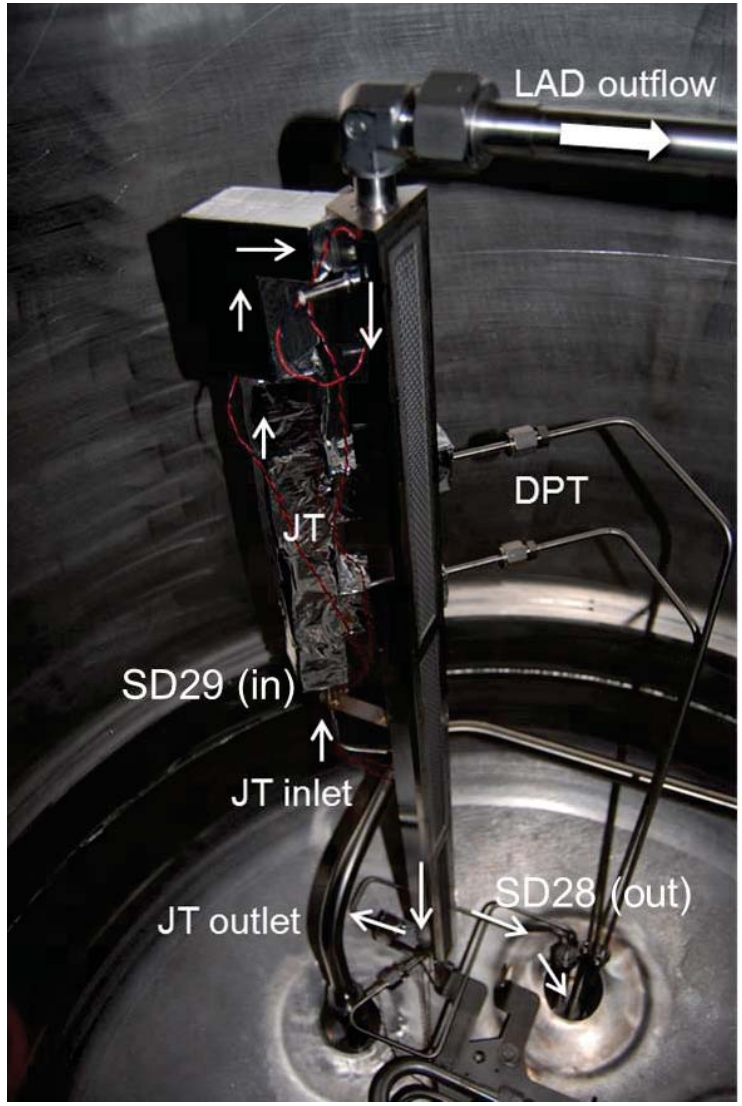

Figure 6: TVS Cooled 325x2300 Channel

The heat exchanger utilized the cooling capacity of the tube fluid to absorb heat from the warmer liquid inside the channel. The heat exchanger was composed of a coiled tube-in-shell counterflow design as shown in Figure 4. The tube side was the coil and the shell side was the warmer liquid flowing from the tank across the screen into the channel. The warm fluid entered the LAD, in and around the coils, and exited through an outflow line at the top as shown in Figure 6. A fluid-resistive device composed of multiple orifices and internal flow paths was used as the JT orifice. The JT device was designed to allow the control of flow rate based on pressure differential. After the fluid passed through the $\mathrm{J}$, isenthalpic expansion occured, and the drop in local pressure was met with a drop in local saturation temperature, cooling the fluid. Approximately $8.53 \mathrm{~m}(28 \mathrm{ft})$ of wound coil is fit into the channel length. 
As the cool fluid inside the coil makes contact with the relatively warmer walls of the coil, nucleate boiling occurs and induces a phase change inside the tube, which increases the fluid cooling capacity. To model this two-phase fluid convection, the Forster-Zuber correlation was used, along with a nucleate boiling suppression factor $S$ and a two-phase multiplier $F$ where

$$
h_{i}=h_{N B} S+h_{L} F
$$

where $h_{N B}$ is the nucleate boiling heat transfer coefficient and $h_{L}$ is the heat transfer coefficient assuming all liquid flow [28]. The convective heat transfer of the warmer LAD fluid outside the tube was calculated using the Churchill and Bernstein relation of fluid flow around a bank of tubes from [29]. For counter-flow heat exchangers where boiling was occurring on one side, the effectiveness was calculated with the relation:

$$
\varepsilon=1-e^{-N T U}
$$

Knowledge of the effectiveness, along with the hot (LAD channel liquid) and cold (liquid inside TVS coil) fluid temperatures, allowed one to calculate the overall heat transfer:

$$
\dot{Q}=\varepsilon C_{\min }\left(T_{h, i n}-T_{c, i n}\right)
$$

where $C_{\min }$ is the minimum heat capacity rate of the hot and cold fluids. Finally, after obtaining the heat transfer rate $\dot{Q}$, the resultant temperature of the liquid inside the LAD channel at the LAD channel outlet is:

$$
T_{h, \text { out }}=T_{h, \text { in }}-\frac{\dot{Q}}{\dot{m}_{L A D} c_{p, L A D}}
$$

where $\dot{m}_{L A D}$ is the mass flow rate through the LAD channel and $c_{p, L A D}$ is the specific heat of the liquid in the channel.

Testing was conducted with the LAD vertically oriented inside the tank. Before the liquid level in the tank drops below the top of LAD, the efficiency of the heat exchanger is negligible. When the liquid level drops below the top of the LAD channel, the efficiency of the heat exchanger will increase as a function of tank level drain. This is because the temperature of the liquid inside and outside of the channel is equal below the tank liquid/vapor (L/V) interface. Above the tank $\mathrm{L} / \mathrm{V}$ interface, where one side of the channel is exposed to warm ullage gas, the temperature of the liquid inside the channel will rise relative to the temperature of the liquid below the $\mathrm{L} / \mathrm{V}$ interface. Therefore, as the LAD screen is exposed to warm ullage gas, the overall effective heat transfer length of the coil increases. Expected versus actual performance is presented in Section 6.4 .

\subsection{Test Methodology}


Consistent with Figure 7, the methodology for conducting an inverted LAD outflow test was as follows: The tank was drained through the LAD screen and out of the top of the channel by pressurizing the ullage space. As the liquid level in the tank was decreased, the screen was uncovered and exposed to pressurant gas. Eventually the LAD broke down at a particular liquid level. A sight glass and camera located within the test tank, downstream of the top of the LAD channel, was used to detect the moment a visible bubble breaks through the screen. The inverted outflow configuration was preferred for dynamic outflow tests because the highest pressure differential occurred at the top of the LAD screen, and bubbles that broke through the screen are immediately forced to rise to the top and out of the channel to the sight glass. However, the sight glass itself resided in warmer ullage space, which could complicate post-test analysis.

Therefore to conduct an inverted LAD outflow test, the tank was first filled with $\mathrm{LH}_{2}$, saturated to ambient pressure. Then the desired liquid temperature was achieved by simply setting the ullage pressure to the desired saturation pressure under back pressure control, and allowing the liquid to naturally absorb parasitic heat leak. As shown in Figure 8, heaters mounted on the tank wall were used to elevate the liquid temperature by allowing the liquid to absorb heat over night. Once the liquid was conditioned, the ullage was pressurized with gaseous helium (GHe) to the desired tank pressure in order to subcool the liquid for LAD outflow. The desired LAD channel was then chosen. The tank was drained through the LAD while the liquid level was still sufficiently above the top of the channel in order to prechill the outflow lines and Venturi flow meter located downstream of the LAD. The desired LAD mass flow rate was chosen by adjusting the control valves located downstream of the flow meter. When the flow rate was constant and steady

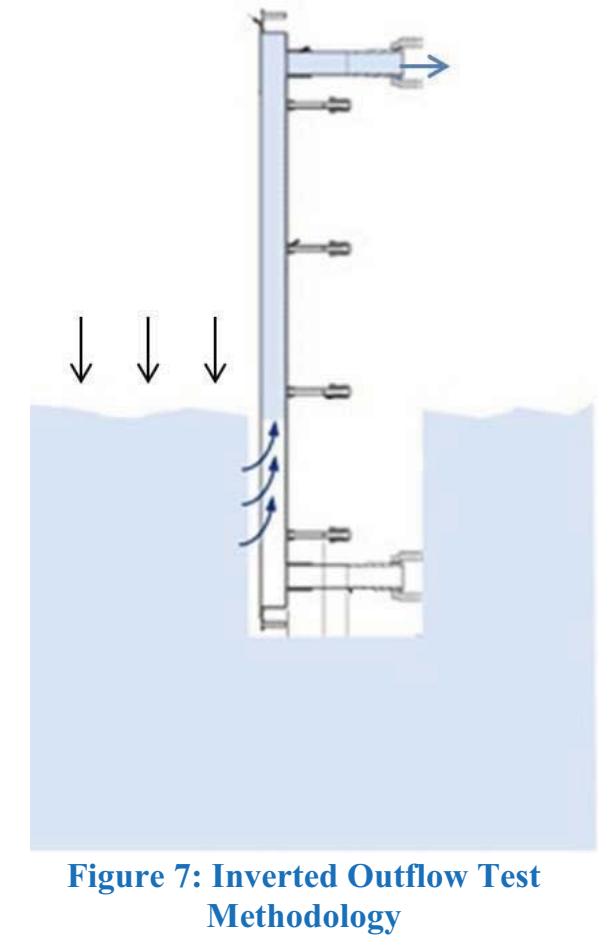

for a period of at least 5 minutes, outflow tests commenced. If the lines downstream were not sufficiently prechilled before the tank liquid level was below the top of the channel, the test was aborted because the warm plumbing downstream of the channel would produce bubbles inside of the sight glass, complicating results. LAD outflow was sampled in real time using a monitor inside of the control room; eventually a GHe bubble would break through the screen at a particular liquid fill level in the tank, corresponding to both visualization in the sight glass and change in the differential pressure measurement across the screen. The time at breakthrough was noted and synchronized with the video to compare with the data during post-test analysis. Two breakdown times were recorded, once at the first GHe visible bubble, and once at total LAD channel breakdown where a constant stream of pressurant gas bubbles were visible in the sight glass. Once the LAD was sufficiently broken down, flow through the LAD ceased, the tank was refilled above the top of the channel, and testing was conducted at a different mass flow rate or liquid temperature. 


\subsection{Facility and Test Article}

Inverted vertical outflow LAD testing was conducted at the Small Multipurpose Research Facility (SMiRF) at the NASA Glenn Research Center (GRC) in Cleveland, OH. Both LAD

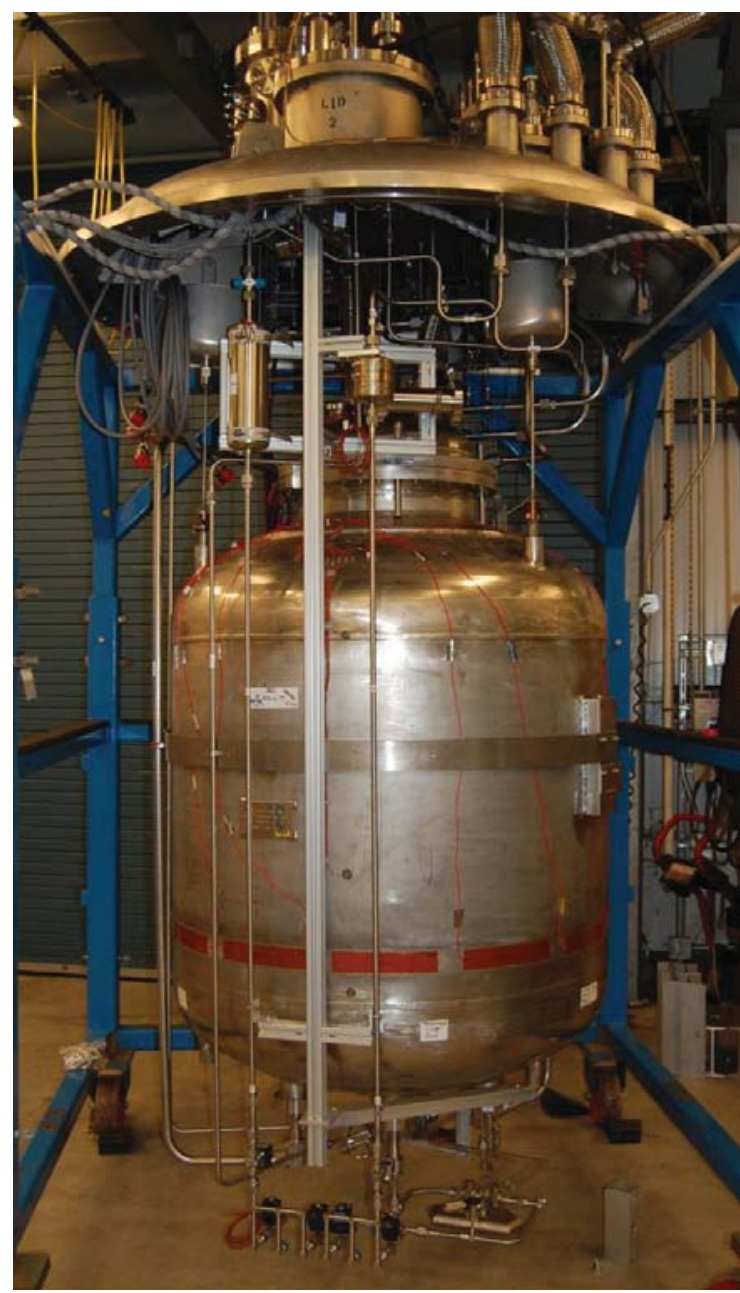

Figure 8: $\mathrm{LH}_{2}$ Test Tank

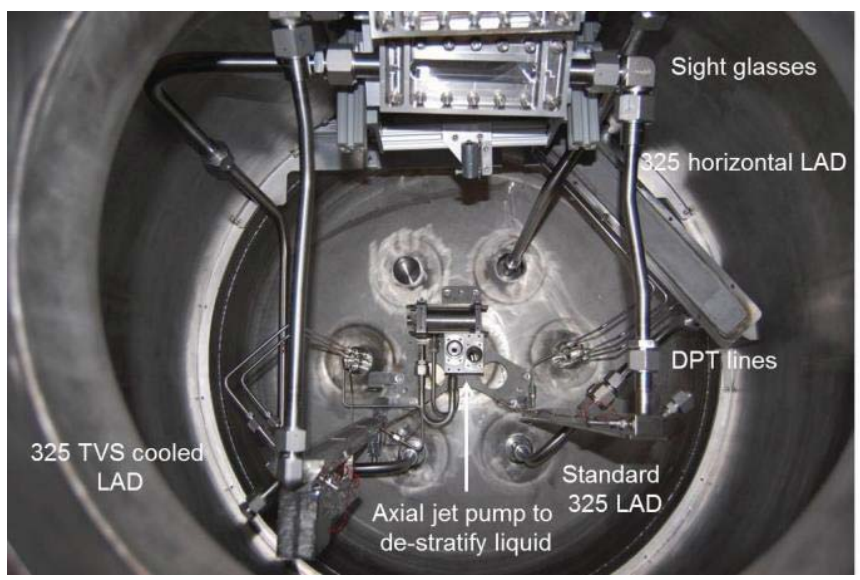

Figure 9: Test Hardware inside Test Tank

channels were vertically mounted inside a 487 gallon, $800 \mathrm{kPa}$ (115 psi) rated, SS tank, with a maximum expected operating pressure (MEOP) of $550 \mathrm{kPa}(80 \mathrm{psi})$ as shown in Figure 8. The LADs and sight glass are shown in Figure 9.

An axial jet was used to de-stratify the liquid propellant, if needed. Orange Kapton strip heaters were mounted to the tank walls and were used to condition the propellant to warmer liquid temperatures, as shown in Figure 8. Although not shown, several layers of multilayer insulation were then added to the tank after hardware assembly to reduce heat leak into the tank. After all test hardware was assembled and mounted inside the test tank, the tank was

mounted from a vacuum chamber (VC) lid as shown in Figure 8. The vacuum lid and test tank were then inserted inside the cryoshroud inside the SMiRF vacuum chamber in order to simulate a LEO temperature of $250 \mathrm{~K}$ and pressure of $1 \times 10^{-6}$ torr.

Pressure of the liquid inside the test tank was controlled through a proportional-integralderivative (PID) loop by pressurizing the ullage space with GHe. Temperature of the liquid was controlled by allowing the liquid to simply absorb parasitic heat leak. Mass flow rate through the LAD was controlled through a series of back pressure control valves. The flow rate through the JT device for the 325 TVS cooled LAD was controlled through the pressure difference between tank and vacuum line.

\subsection{Instrumentation and Data Acquisition}


Table 2 lists critical instrumentation for the vertical LAD outflow tests. Ullage pressure was measured in order to deduce the pressure at the LAD screen. Pressure and temperature inside the outflow line was measured to ensure that there was vapor free liquid flow at the Venturi prior to the start of the test. A differential pressure transducer (DPT) was mounted across the JT orifice to determine the flow rate through the heat exchanger. Stream diodes were mounted upstream of the JT orifice and downstream of the cooling coil to assess the effectiveness of the TVS heat exchanger. Silicon diodes were spaced approximately $5.0 \mathrm{~cm}$ apart on a vertical rake and were used to measure both the bulk liquid temperature as well as height of the liquid level in the tank. Load cells were also used to measure mass and thus served as a redundant measure of the liquid level. The vertical diode rake was used as the primary liquid level sense method at LAD breakdown while the load cells were used to interpolate liquid level in between the diodes. All pressures, DPTs, temperatures, and flows were recorded at $2 \mathrm{~Hz}$ shown in Figure 10. A monochromatic camera was used to view the sight glass in real time. The camera system was modified to operate safely at $\mathrm{LH}_{2}$ temperatures.

The pressure in the ullage and outflow line was measured to within $4.6 \mathrm{kPa}(0.667 \mathrm{psia})$. All DPTs measured pressure to within $1 \%$ of the full scale range. SD12, 14, and $25-29$ measured temperature to within $0.1 \mathrm{~K}$; all diodes in the vertical rake measured temperature to within $0.5 \mathrm{~K}$. Liquid height was measured to within $2.7 \mathrm{~cm}\left(1.067^{\prime \prime}\right)$ using the diodes. Uncertainty analysis was performed on the load cell calculated liquid level based on the internal volume of the tank and mass of the $\mathrm{LH}_{2}$. The uncertainty in liquid level between consecutive diodes is estimated to be $0.40 \mathrm{~cm}\left(0.154^{\prime}\right.$ ') in the coldest liquid temperatures and $1.27 \mathrm{~cm}(0.5$ ') $)$ in the warmest liquid temperatures. Uncertainty in the LAD liquid flow rate was estimated based on the Venturi equation and was approximately $2-3 \%$ of the measured value across the range of tests.

\subsection{Results and Discussion}

\subsection{Test Matrix and Test Conditions}

Test conditions for the inverted 1-g vertical outflow tests are shown in Table 3. The test matrix is divided between the TVS cooled $325 \times 2300$ and standard $325 \times 2300$ channel test runs. For clarity, the table is organized and color coded by saturation temperature (and pressure), and then organized by flow rate. As shown, vertical outflow tests were conducted at fixed fluid saturation temperatures of $20.3,21.4,22.9$, and $24.2 \mathrm{~K}$. Breakdowns were attempted at several different controlled mass flow rates representative of the previously referenced mission architectures, as shown in Table 3. Tank pressure was generally chosen to be sufficiently greater than saturation pressure to suppress liquid boiling at the LAD screen. For the TVS cooled 325x2300 LAD, three tests were repeated at the same liquid temperature to directly compare performance with and without the TVS engaged. To examine the effect of LAD performance gain in bubble point pressure due to pressurizing and subcooling with the noncondensible pressurant $[9,14,19,21]$, three tests were repeated for the TVS cooled 325x2300 channel at elevated tank pressure. 


\begin{tabular}{|c|c|c|c|c|}
\hline Channel & Units & & Uncertainty & Purpose \\
\hline \multicolumn{5}{|l|}{ PTs } \\
\hline $\mathrm{FH} 103$ & 100 & psia & \pm 0.667 psia & Tank Ullage pressure \\
\hline P12 & $0-100$ & psia & \pm 0.667 psia & VJ manifold pressure \\
\hline P13 & $0-100$ & psia & \pm 0.667 psia & Venturi static $P$ \\
\hline & & & & \\
\hline \multicolumn{5}{|l|}{ DPTs } \\
\hline DPT06A & $0-10$ & inch $\mathrm{H} 2 \mathrm{O}$ & \pm 0.0073 in $\mathrm{H} 2 \mathrm{O}$ & 325 LAD Head pressure \\
\hline DPT08A & $0-10$ & inch $\mathrm{H} 2 \mathrm{O}$ & \pm 0.0073 in $\mathrm{H} 2 \mathrm{O}$ & 325F LAD Head pressure \\
\hline DPT9 & $0-50$ & psid & \pm 0.667 psia & Joule Thompson DPT \\
\hline DPT13A & $0-20$ & psid & \pm 0.667 psia & Venturi DPT High \\
\hline DPT13B & $0-10$ & inch $\mathrm{H} 2 \mathrm{O}$ & \pm 0.0073 in $\mathrm{H} 2 \mathrm{O}$ & Venturi DPT Med \\
\hline \multicolumn{5}{|c|}{ SILICON DIODES } \\
\hline SD25 & $15-300$ & K & $\pm 0.1 \mathrm{~K}$ & 325 liquid screen side temp \\
\hline SD27 & $15-300$ & K & $\pm 0.1 \mathrm{~K}$ & $325 F$ liquid screen side temp \\
\hline SD28 & $15-300$ & K & $\pm 0.1 \mathrm{~K}$ & TVS in \\
\hline SD29 & $15-300$ & K & $\pm 0.1 \mathrm{~K}$ & TVS out \\
\hline SD12 & $15-300$ & K & $\pm 0.1 \mathrm{~K}$ & Flight 325 LAD Temperature @ venturi \\
\hline SD14 & $15-300$ & K & $\pm 0.1 \mathrm{~K}$ & 325 LAD Temperature @ venturi \\
\hline \multicolumn{5}{|c|}{ FLOW METERS } \\
\hline FH001 & & $\mathrm{lbm} / \mathrm{s}$ & $\sim 2 \%$ of reading & outflow for $325 \times 2300$ vertical LAD \\
\hline FHOO3 & & $\mathrm{lbm} / \mathrm{s}$ & $\sim 2 \%$ of reading & outflow for $325 \times 2300$ flight vertical LAD \\
\hline
\end{tabular}

Table 2: Instrumentation List

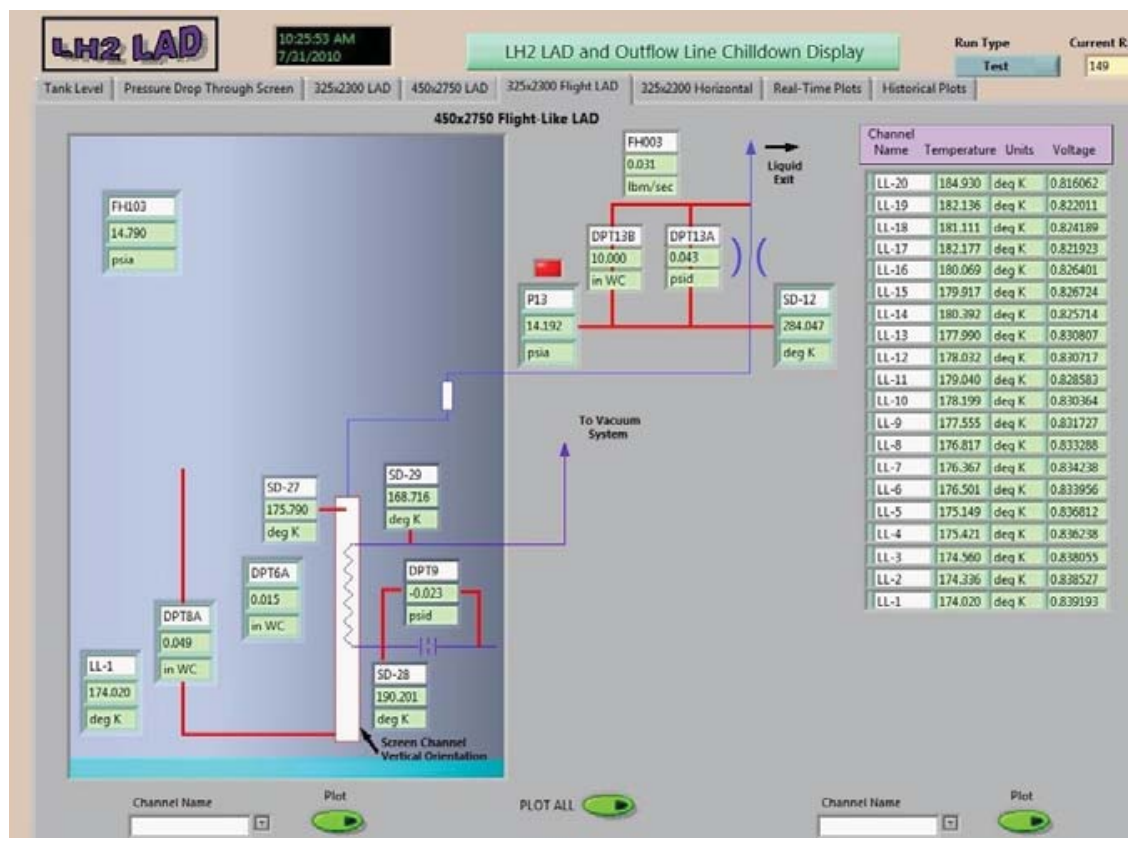

Figure 10: DAQ Screenshot for TVS Cooled 325x2300 LAD Channel 


\begin{tabular}{|c|c|c|c|c|c|c|c|}
\hline & & & Ptank & Psat & Tsat & Flow Rate & Notes \\
\hline Test \# & Day & Date & kPa [psia] & kPa [psia] & {$[\mathrm{K}]$} & $\mathrm{kg} / \mathrm{s}[\mathrm{lbm} / \mathrm{s}]$ & \\
\hline \multicolumn{8}{|c|}{$325 \times 2300$} \\
\hline 5 & 3 & $8 / 1 / 2012$ & 204.1 [29.6] & $103.4[15]$ & 20.3 & $0.0241[0.053]$ & \\
\hline 4 & 3 & $8 / 1 / 2012$ & $202.7[29.4]$ & $103.4[15]$ & 20.3 & $0.0364[0.08]$ & \\
\hline 9 & 5 & $8 / 3 / 2012$ & 202.0 [29.3] & $103.4[15]$ & 20.3 & 0.0414 [0.091] & \\
\hline 22 & 15 & $8 / 17 / 2012$ & $240.0[34.8]$ & $137.9[20]$ & 21.4 & $0.0418[0.092]$ & \\
\hline 14 & 9 & $8 / 9 / 2012$ & 233.7 [33.9] & $137.9[20]$ & 21.4 & $0.0486[0.107]$ & \\
\hline 20 & 13 & $8 / 15 / 2012$ & $282.0[40.9]$ & $206.8[30]$ & 22.9 & $0.0123[0.027]$ & \\
\hline 27 & 19 & $8 / 23 / 2012$ & $270.3[39.2]$ & $206.8[30]$ & 22.9 & $0.0491[0.108]$ & \\
\hline 15 & 10 & $8 / 10 / 2012$ & $344.7[50]$ & $275.8[40]$ & 24.2 & $0.0167[0.0367]$ & \\
\hline 24 & 18 & $8 / 22 / 2012$ & $343.4[49.8]$ & $275.8[40]$ & 24.2 & $0.0223[0.049]$ & \\
\hline 18 & 12 & $8 / 14 / 2012$ & $348.2[50.5]$ & $275.8[40]$ & 24.2 & $0.034[0.0747]$ & \\
\hline \multicolumn{8}{|c|}{$325 \times 2300$ TVS Cooled } \\
\hline 7 & 4 & $8 / 2 / 2012$ & 204.8 [29.7] & $103.4[15]$ & 20.3 & $0.019[0.042]$ & \\
\hline 2 & 1 & $7 / 30 / 2012$ & $173.1[25.1]$ & $103.4[15]$ & 20.3 & $0.0227[0.05]$ & \\
\hline 1 & 1 & $7 / 30 / 2012$ & $139.3[20.2]$ & $103.4[15]$ & 20.3 & $0.0364[0.08]$ & \\
\hline 19 & 12 & $8 / 14 / 2012$ & $242.7[35.2]$ & $137.9[20]$ & 21.4 & $0.015[0.033]$ & \\
\hline 3 & 2 & $7 / 31 / 2012$ & 236.5 [34.3] & $137.9[20]$ & 21.4 & $0.02[0.044]$ & \\
\hline 21 & 14 & $8 / 16 / 2012$ & 236.5 [34.3] & $137.9[20]$ & 21.4 & $0.0286[0.063]$ & \\
\hline 12 & 7 & $8 / 7 / 2012$ & $271.7[39.4]$ & $206.8[30]$ & 22.9 & $0.0414[0.091]$ & \\
\hline 26 & 19 & $8 / 23 / 2012$ & $273.0[39.6]$ & $206.8[30]$ & 22.9 & $0.0495[0.109]$ & \\
\hline 23 & 17 & $8 / 21 / 2012$ & $273.7[39.7]$ & $206.8[30]$ & 22.9 & $0.05[0.11]$ & \\
\hline 8 & 5 & $8 / 3 / 2012$ & 339.9 [49.3] & $275.8[40]$ & 24.2 & $0.0132[0.029]$ & \\
\hline 6 & 4 & $8 / 2 / 2012$ & $339.2[49.2]$ & $275.8[40]$ & 24.2 & $0.025[0.055]$ & \\
\hline 17 & 11 & $8 / 13 / 2012$ & $344.7[50]$ & 103.4 [15] & 20.3 & $0.0141[0.031]$ & Subcooled run \\
\hline 16 & 10 & $8 / 10 / 2012$ & $344.7[50]$ & $103.4[15]$ & 20.3 & $0.0263[0.058]$ & Subcooled run \\
\hline 25 & 18 & $8 / 22 / 2012$ & $332.3[48.2]$ & 103.4 [15] & 20.3 & $0.055[0.121]$ & Subcooled run \\
\hline 13 & 7 & $8 / 7 / 2012$ & 204.1 [29.6] & 103.4 [15] & 20.3 & $0.03[0.066]$ & TVS off \\
\hline 11 & 6 & $8 / 6 / 2012$ & 203.4 [29.5] & $103.4[15]$ & 20.3 & $0.0386[0.085]$ & TVS off \\
\hline 10 & 5 & $8 / 3 / 2012$ & 202.7 [29.4] & $103.4[15]$ & 20.3 & $0.0414[0.091]$ & TVS off \\
\hline
\end{tabular}

Table 3: Test Matrix

\subsection{Pre and Post Test IPA Tests}

Before submersion in $\mathrm{LH}_{2}$ both channels were cold shocked in $\mathrm{LN}_{2}$ and then bubble point tested in IPA as shown in Figure 5. The method of bubble point testing is outlined in [12]. Test results are shown in Figure 11. The black line is the prediction curve based on surface tension values based on the local temperature of the IPA during tests and $325 \times 2300$ pore diameters from [12]. Error bars are also plotted for reference. As shown, the standard 325x2300 channel exceeded predicted performance before testing; but after the channel was tested in $\mathrm{LH}_{2}$, the performance degraded by $4.9 \%$. Meanwhile, the TVS cooled LAD did not exceed the expectation value before or after $\mathrm{LH}_{2}$ testing, with a degradation factor of $19 \%$.

Note from Figure 11 that the two channels did not have the same exact bubble point pressure, before or after $\mathrm{LH}_{2}$ tests, despite both being manufactured from the same raw batch of $325 \times 2300$ screen material. The difference in performance pre-test was just outside experimental uncertainty of $3 \%$. However the difference in performance post-test was greater than $15 \%$. The change in 
performance of both channels was likely due to the differential contractions and expansions of the screen wires after being exposed to multiple thermal cycles during $\mathrm{LH}_{2}$ testing. The reduction in performance could also be due to wire embrittlement at $\mathrm{LH}_{2}$ temperatures. It is fairly certain that degradation in bubble point occurred after $\mathrm{LH}_{2}$ tests, and not before, since both channels performed relatively similar at similar $\mathrm{LH}_{2}$ test conditions as reported in Section 6.3, and because experimental performance compared quite well with model predictions from [13]. Nonetheless, since the channels had slightly different pretest bubble points, it is not advisable to compare the breakdown points on an absolute scale, but rather consider relative trends in performance.
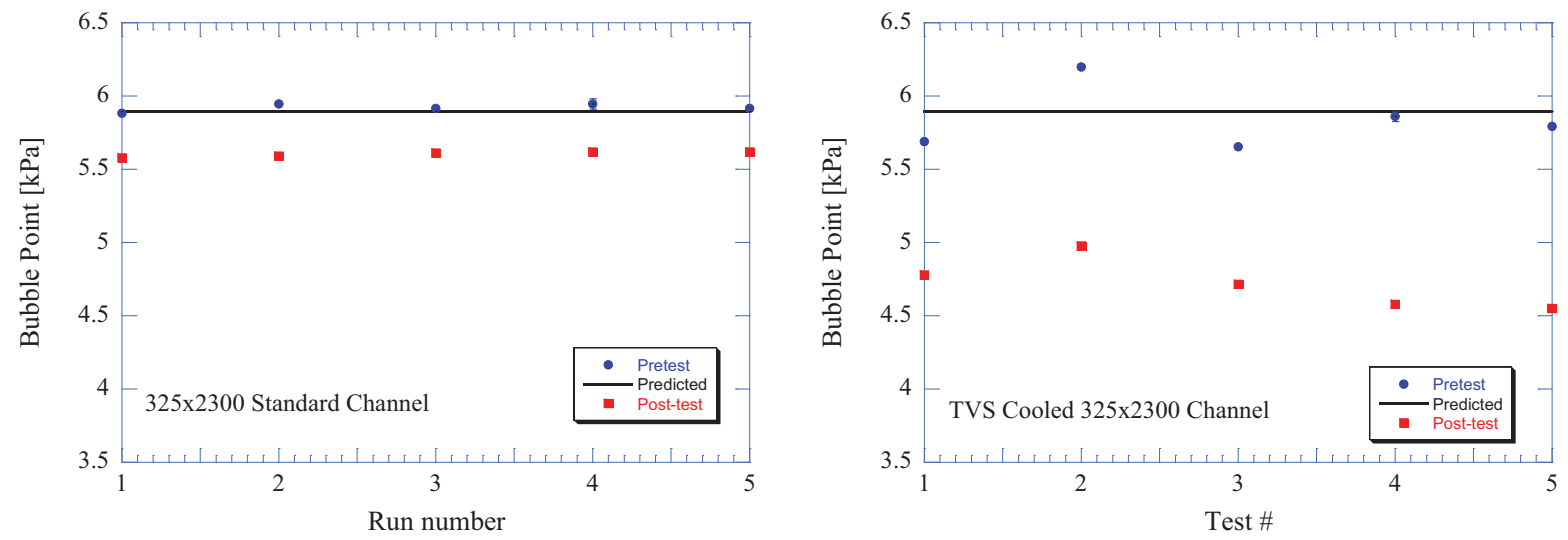

Figure 11: Pre and Post IPA Bubble Point Testing of the a) 325x2300 Standard Channel b) TVS Cooled $325 \times 2300$ Channel. The black line is the prediction curve based on the temperature of the IPA and pore diameter from [12].

\subsection{1-g Inverted Outflow Tests}

Inverted 1-g LAD outflow test results are plotted in Figures 12 and 13. Performance is measured in terms of the vertical exposed screen height as a function of liquid temperature and mass flow rate. Therefore, longer exposed screen heights equate to higher performance, since the LAD is able to sustain outflow for a longer period of time before gas ingestion. Alternatively, one could also use distance from the bottom of the LAD channel to gauge performance, which is simply the total channel length minus the exposed screen height.

Figure 12 plots the exposed screen length for the $325 \times 2300$ standard channel as a function of tank liquid temperature and LAD outflow rate. Figure 12a plots the breakdown point the moment a pressurant gas bubble was visible in the sight glass while Figure $12 \mathrm{~b}$ plots the breakdown point when the LAD had ingested a steady stream of bubbles (i.e. complete failure). Error bars are plotted for reference. The three trends are as follows: First, the breakdown point is dominated by liquid temperature, as longer exposed screen lengths are achievable in colder liquid temperatures since higher surface tensions are achievable in colder temperatures. The amount of exposed screen length decreases linearly with increasing tank liquid temperature. At the warmest liquid temperature tested of $24.2 \mathrm{~K}$, the LAD breakdown point has shifted by about $15 \mathrm{~cm}$, or about $16 \%$ of the total LAD channel height. Second, the breakdown point is also dependent on the mass flow rate through the LAD. At a given fixed liquid temperature, the standard $325 \times 2300$ channel broke down at higher flow rates. Over a change in flow rate from $\sim 0.01 \mathrm{~kg} / \mathrm{s}$ to $0.04 \mathrm{~kg} / \mathrm{s}$, 
breakdown point shifts by approximately $4 \%$ of the total channel length. This shift in the breakdown point with increased mass flow rate is simply due to an increase in the FTS pressure drop across the channel, which increases as the amount of screen is exposed to vapor (i.e. less cross sectional area for the liquid to flow through the screen). The effect of mass flow rate is consistent across the range of liquid temperatures tested here. Third, when comparing Figure 12a to $12 \mathrm{~b}$, the amount of exposed screen length increases from the point at which the channel ingests a single GHe bubble to the total breakdown point, as expected. The average gain in performance from single bubble ingestion to total breakdown is approximately $4.8 \mathrm{~cm}$ or $5 \%$ of the total LAD height. The trends here agree well with the model predicted breakdown points [13].
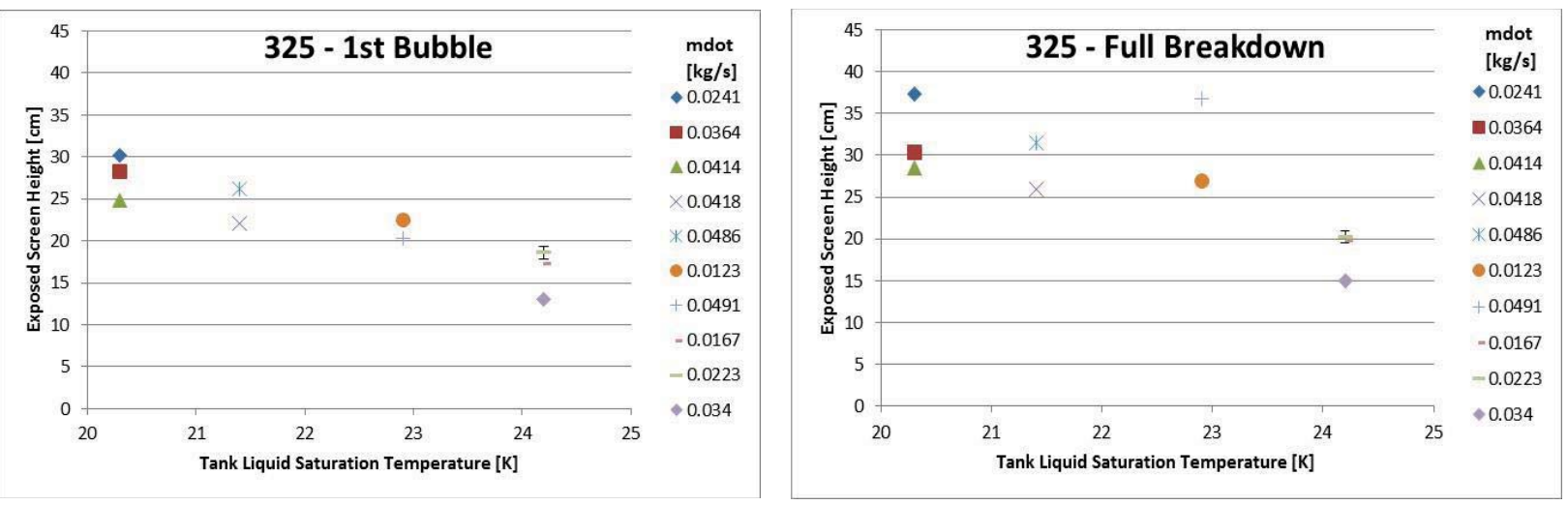

Figure 12: Exposed Screen Height as a Function of Tank Liquid Conditions and Mass Flow Rate Through the LAD at a) First GHe Bubble Ingestion and b) Total LAD Breakdown for the Standard $325 \times 2300$ Channel
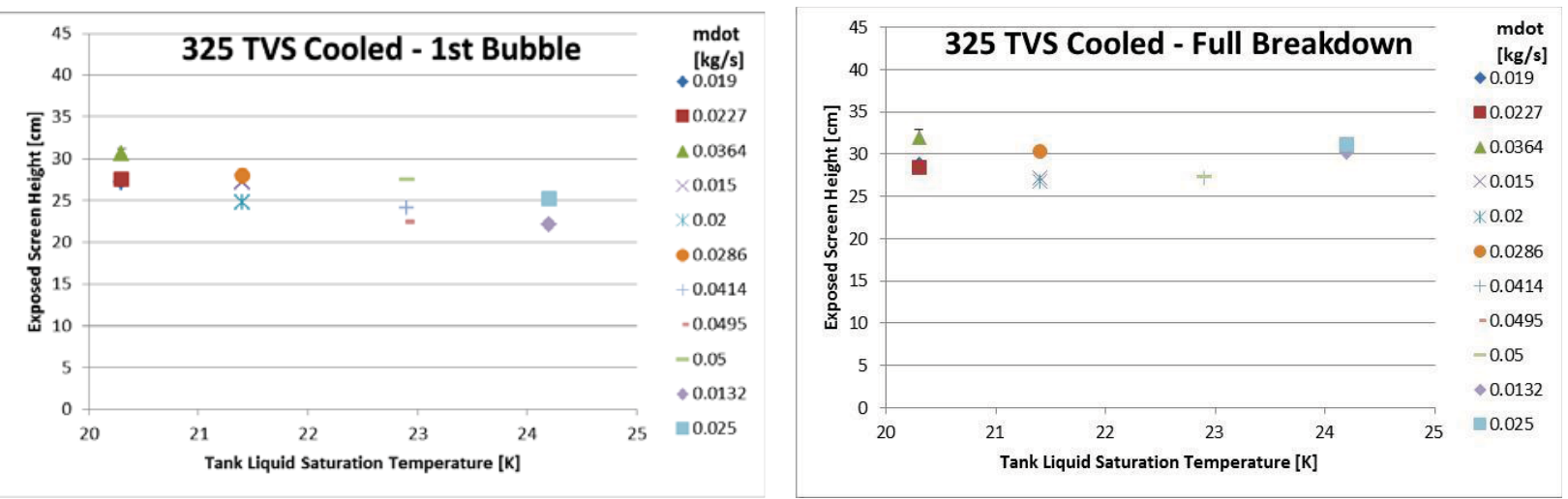

Figure 13: Exposed Screen Height as a Function of Tank Liquid Conditions and Mass Flow Rate Through the LAD at a) First GHe Bubble Ingestion and b) Total LAD Breakdown for the TVS Cooled $325 \times 2300$ Channel

Figure 13 plots the exposed screen length for the TVS cooled $325 \times 2300$ channel as a function of tank liquid temperature and LAD outflow rate, and Table 4 summarizes TVS performance. For all points, the TVS was engaged, and the flow rate through the TVS coil was approximately the same, $1.14 \mathrm{~g} / \mathrm{s}$. However the amount of cooling is slightly different due to different TVS inlet liquid temperatures. The TVS inlet pressure was the tank pressure, and the outlet pressure was 14 $\mathrm{kPa}$. The four trends are as follows: First, the breakdown point is again dominated by liquid temperature. Second, there again is a secondary dependence on mass flow rate. However, unlike 
the standard $325 \times 2300$ screen channel, higher flow rates lead to longer exposed screen lengths. Higher flow rates cause the TVS cooled channel to break down later. The spread in data is approximately $3 \%$ of the total channel length. This difference in performance with flow rate between the two channels is attributed to the presence of the perforated plate in the TVS cooled channel. Previous studies have shown that the perforated plate enhanced wicking of liquid [30]. As liquid is routed up through the top of the TVS cooled channel, the plate acts to rewet areas of the screen which would dry out, thus extending the point of breakdown. Third, when comparing Figure 13a to $13 \mathrm{~b}$, the amount of exposed screen length increased from the point at which the channel ingests a single GHe bubble to the total breakdown point, as expected. The average gain in performance from single bubble ingestion to total breakdown is approximately $2.9 \mathrm{~cm}$ or $3 \%$ of the total TVS cooled LAD height. Fourth, comparing Figure 13a to 12a, the slope of the breakdown points flattens out for the TVS cooled channel relative to the standard channel. This is proof that the TVS cooling enhanced performance of the LAD in warmer liquid temperatures. This implies that the TVS cooling can provide nearly the same performance in warmer liquid temperatures where the channel has a higher tendency to break down than it does in colder liquid temperatures. In addition, when comparing Figures $13 \mathrm{a}$ to $13 \mathrm{~b}$, the perforated plate and TVS cooling also lead to longer exposed screen heights at the warmest liquid temperatures. The trends here do not agree well with the model predicted breakdown points from [13] because the model doesn't account for the additional wicking.

\begin{tabular}{|c|c|c|c|c|c|c|c|}
\hline & Ptank & Psat & $T$ LAD in & T LAD Out & mdot LAD & delta T JT & delta P JT \\
\hline Test \# & [kPa] & [kPa] & [K] & [K] & {$[\mathrm{kg} / \mathrm{s}]$} & [K] & [psid] \\
\hline 7 & 204.77 & 103.42 & 20.3 & 20.3 & 0.0191 & 4.61 & 6.44 \\
\hline 2 & 173.06 & 103.42 & 20.3 & 20.3 & 0.0227 & 5.28 & 4.6 \\
\hline 1 & 139.27 & 103.42 & 20.3 & 20.3 & 0.0364 & 4.88 & 6.05 \\
\hline 17 & 344.74 & 103.42 & 20.3 & 20.3 & 0.0141 & 5.22 & 9.9 \\
\hline 16 & 344.74 & 103.42 & 20.3 & 20.3 & 0.0263 & 4.51 & 0.719 \\
\hline 25 & 332.33 & 103.42 & 20.3 & 21.2 & 0.0550 & 5.03 & 0.742 \\
\hline 19 & 242.70 & 137.90 & 21.4 & 21.4 & 0.015 & 6.43 & 5.66 \\
\hline 3 & 236.49 & 137.90 & 21.4 & 21.4 & 0.0200 & 6.08 & 6 \\
\hline 21 & 236.49 & 137.90 & 21.4 & 21.2 & 0.0286 & 6.43 & 5.78 \\
\hline 12 & 271.65 & 206.84 & 22.9 & 22.8 & 0.0414 & 6.18 & 24.4 \\
\hline 26 & 273.03 & 206.84 & 22.9 & 22.9 & 0.0495 & 7.31 & 4.74 \\
\hline 23 & 273.72 & 206.84 & 22.9 & 22.8 & 0.0500 & 7.25 & 4.96 \\
\hline 8 & 339.91 & 275.79 & 24.2 & 23.3 & 0.0132 & 7.05 & 6.28 \\
\hline 6 & 339.22 & 275.79 & 24.2 & 23.8 & 0.0250 & 7.38 & 5.74 \\
\hline
\end{tabular}

Table 4: TVS LAD Performance

\subsection{TVS Efficiency}

To isolate and test the efficiency of the TVS cooling system, six tests were conducted with the TVS cooled LAD channel in $20.3 \mathrm{~K}$ saturated liquid with identical tank pressures of $207 \mathrm{kPa}$ as shown in Table 3. For three of the tests, the TVS cooling was engaged; for three of the tests the TVS was disengaged. Only liquid flow rate through the LAD varied for these tests. Since the two channels had different pretest bubble points, this testing strategy was the only way to directly measure the efficiency of the TVS cooling. Results are plotted in Figure 14. As shown, longer 
exposed screen lengths were achievable with the heat exchanger engaged, as expected. The average difference in performance is approximately $7 \%$ of total channel length. The largest difference in performance was at higher flow rates where the perforated plate was able to wick colder fluid into the screen pores at the top of the channel, thus prolonging the breakdown point relative to slower flow rates.

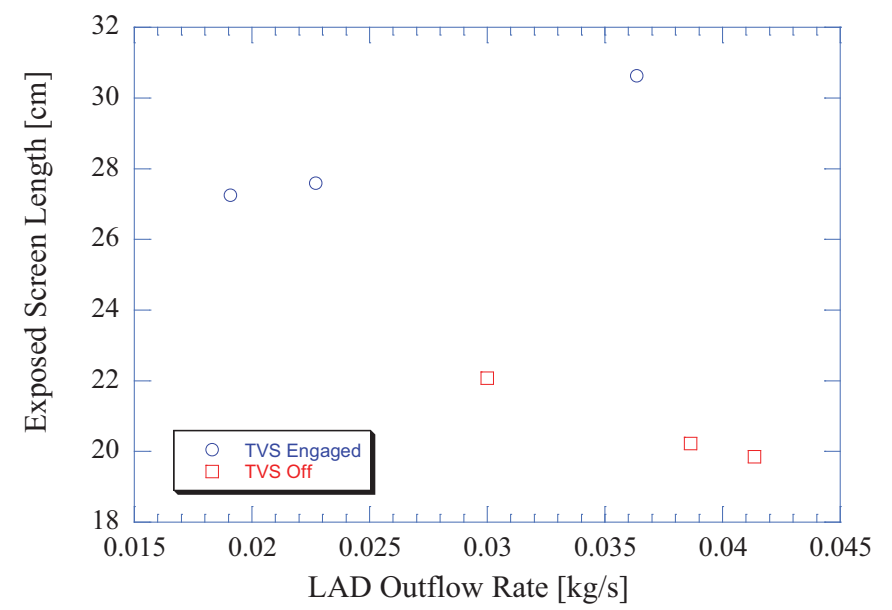

Figure 14: Exposed Screen Height as a Function of Mass Flow Rate through the LAD for the TVS Cooled $325 \times 2300$ Channel with the TVS System Engaged and Disengaged.

The primary purpose of the TVS heat exchanger was to lower the liquid temperature internal to the LAD channel. Therefore, a second way to assess the efficiency of the TVS heat exchanger is to directly compare the measured liquid temperature inside of the channel to the tank bulk liquid temperature during steady outflow. Of the primary 11 tests run with the TVS cooled LAD channel, only the two runs in the warmest liquid temperature of $24.2 \mathrm{~K}$ showed noticeable differences outside the experimental uncertainty between the two temperatures. These points are plotted in Figure 15 along with heat exchanger model predicted performance from Equation 11. As shown there was at most $1 \mathrm{~K}$ (or $4 \%$ of bulk liquid temperature) difference between the liquid temperatures when the TVS was engaged during steady state outflow. Meanwhile the idealized model predicted a higher temperature difference of $2-3 \mathrm{~K}$. The disparity is likely due to the model assumptions and idealizations. The model prediction curves assume a full $91 \mathrm{~cm}$ exposed length for heat exchange, but examination of Figures 12 and 13 indicate that at most 1/3 of the LAD was exposed during outflow tests. This would limit the actual efficiency of the heat exchanger. The LADs broke down earlier than anticipated because the FTS pressure drop was 35\% higher than anticipated at $\mathrm{LH}_{2}$ temperatures [13]. Nonetheless, the TVS heat exchanger is still shown to reduce the effective liquid temperature inside of the channel and prolong breakdown by as much as $7 \%$ of the total channel length.

\subsection{Subcooling Effect}

Previous bubble point tests conducted in $\mathrm{LH}_{2}$, [14], $\mathrm{LOX}$ [19], and $\mathrm{LCH}_{4}$ [21] showed an increase in bubble point pressure proportional to the level of subcooling the liquid at the screen interface. Thus the gain in bubble point is proportional to the difference between the total pressure and saturation pressure of the liquid at the screen: 


$$
\frac{\Delta P_{B P}(P)}{\Delta P_{B P, N B P}} \propto\left(P-P_{S A T}\right)
$$

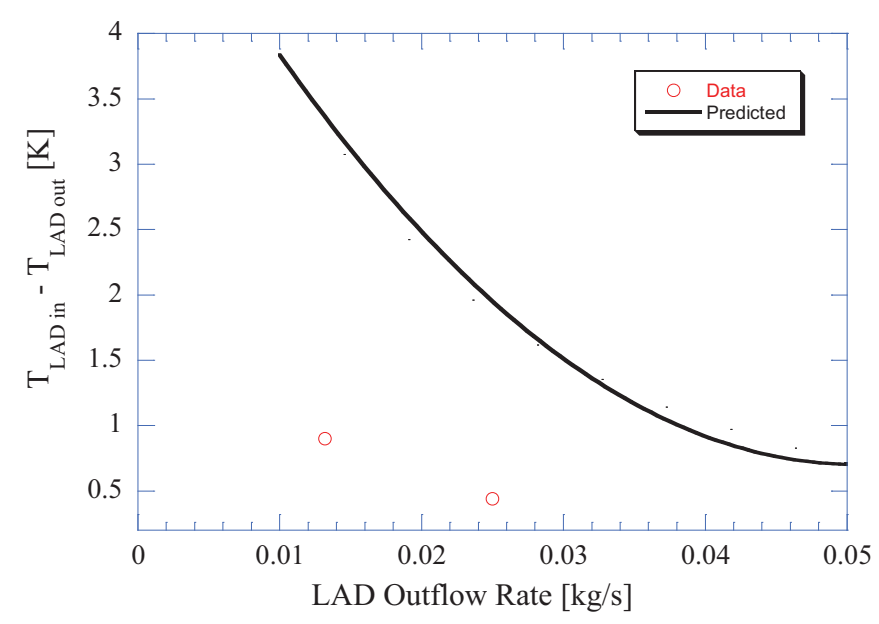

Figure 15: TVS Heat Exchanger Efficiency in Terms of the Difference between the Bulk Liquid in the Tank and the Liquid inside the LAD Channel. Data points are for $24.2 \mathrm{~K}$ liquid temperature tests.

The gain in bubble point pressure is linear with the pressure difference, so higher partial pressures of $\mathrm{GHe}$ equate to higher bubble points. Thus it was highly desired to demonstrate whether or not the gain in the static bubble point pressure would translate into a gain in performance in a dynamic outflow environment. Therefore, higher bubble point pressures should translate into longer exposed screen lengths.

To test this hypothesis, six tests were conducted in normally saturated $\mathrm{LH}_{2}(20.3 \mathrm{~K})$ using the TVS cooled $325 \times 2300$ channel. Three tests were performed with a total tank pressure of $207 \mathrm{kPa}$ (30 psia), $102 \mathrm{kPa}$ of subcooled margin, and three with tank pressure of $345 \mathrm{kPa}$ (50 psia), 244 $\mathrm{kPa}$ subcooled margin. TVS flow rate was identical for all six tests. As shown in Figure 16, longer exposed screen lengths were achievable in higher tank pressures; there is $4-5 \%$ difference in exposed screen height when subcooling the liquid by an additional $138 \mathrm{kPa}$.

To compare this gain to the static bubble point gain, a curve was fit to $325 \times 2300 \mathrm{GHe} / \mathrm{LH}_{2}$ subcooled bubble point data from [15]. Figure 17 plots Equation 12, the bubble point at a given pressure divided by the corresponding normal boiling point bubble point value versus the pressure difference between the liquid saturation pressure and total tank pressure (level of subcooling). As shown, the data from [15] only extends to a pressure difference of about 100 $\mathrm{kPa}$, so the curve fit extrapolates to tank pressures of $207 \mathrm{kPa}$ and $345 \mathrm{kPa}$ under which dynamic outflow tests were conducted. Table 5 summarizes results; at a total tank pressure of $207 \mathrm{kPa}$, there is a $3 \%$ gain in bubble point pressure from the NBP value; at a tank pressure of $345 \mathrm{kPa}$, there is an $8 \%$ gain over the NBP value. Between the two pressures, the relative gain in static bubble point pressure is $4.5 \%$, which compares nicely with the $4-5 \%$ gain during dynamic outflow tests shown in Figure 16. Therefore, the gain in exposed screen length in the dynamic environment indeed directly related to the gain in static bubble point pressure. 


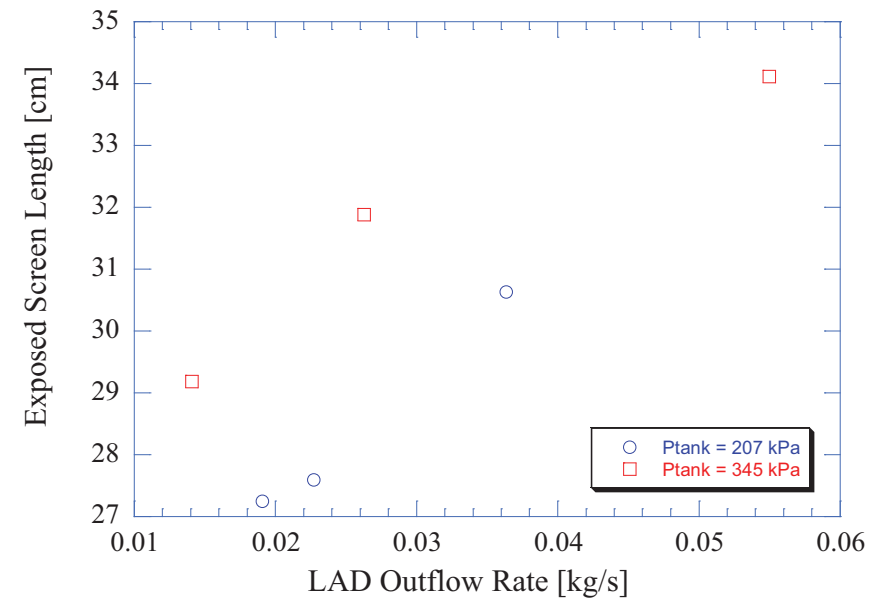

Figure 16: Gain in Dynamic LAD Performance Due to Subcooling the Bulk Liquid in the Tank.

\begin{tabular}{|c|c|c|c|}
\hline Psat & Ptank & delta P & Gain from NBP \\
\hline$[$ kPa] & {$[\mathbf{k P a}]$} & {$[\mathbf{k P a}]$} & $\mathbf{\%}$ \\
\hline 103.42 & 206.84 & 103.42 & 1.034 \\
\hline 103.42 & 344.74 & 241.32 & 1.079 \\
\hline
\end{tabular}

Table 5: Gain in Bubble Point Pressure as a Function of Level of Subcooling

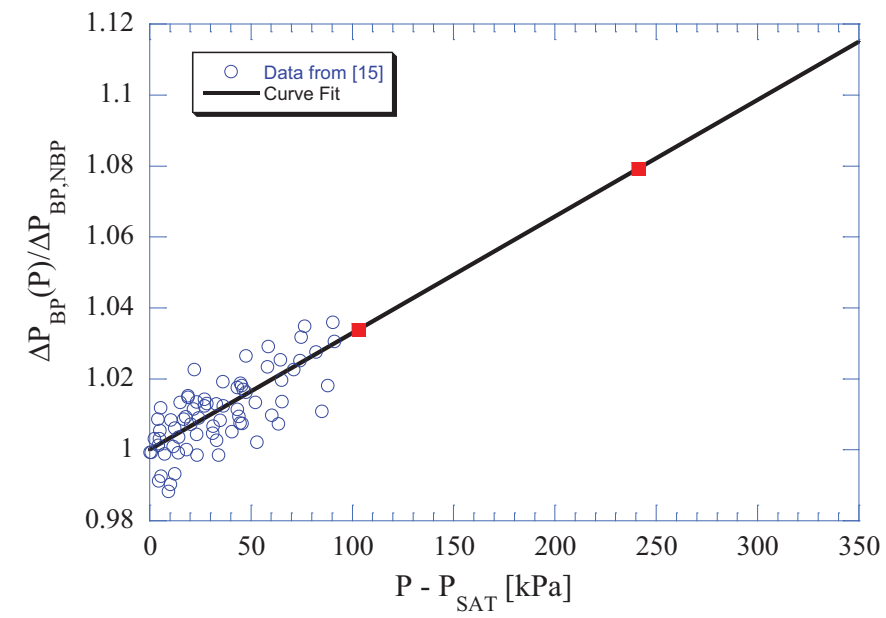

Figure 17: Gain in Static LAD Performance in $\mathbf{L H}_{2}$ due to Subcooling the Bulk Liquid at the Screen Liquid Vapor Interface.

\subsection{Conclusions}

This work characterized two $325 \times 2300$ screen channel LADs in a dynamic outflow environment over a wide range of liquid temperatures, pressures, and outflow rates for an in-space $\mathrm{LH}_{2}$ propellant tank. Results indicate that the breakdown point is dominated by the temperature of the liquid, with a second order effect on the mass flow rate through the LAD channel. For both 
channels, the highest performance is always obtained in colder liquid states. For the standard $325 \times 2300$ channel, higher flow rates caused the LAD to breakdown earlier, while for the TVS cooled $325 \times 2300$ channel, higher flow rates prolonged the breakdown point. The presence of the perforated plate in the TVS cooled LAD is believed to enhance wicking and thus screen retention during outflow. For all operating conditions, the TVS cooled LAD demonstrated higher performance over the standard channel, due to the presence of the internal heat exchanger. Higher exposed screen lengths were achievable with the TVS system engaged. The TVS system cooled the liquid inside the channel by $1 \mathrm{~K}$ in $24 \mathrm{~K}$ tank liquid, and prolonged breakdown by as much as $6 \%$ of the total channel length. In addition, the TVS cooling provided nearly the same performance in warm liquid as in colder liquid as shown by the flattening of the slope in Figure 13. Subcooling the liquid at the screen is also shown to improve performance proportional to the difference between total pressure and liquid saturation pressure.

Results here have direct implications for future LAD design for the proposed in-space $\mathrm{LH}_{2}$ fuel depots. Both the presence of the internal LAD heat exchanger and the perforated plate prolonged the breakdown point, which implies that the LAD can sustain higher flow rates or flow for longer periods before gas ingestion. When compared to updated model predictions from [13], the screen channel LADs performed well within design expectations and are thus capable of delivering high flow rates for low surface tension cryogenic propellants.

\subsection{Acknowledgements}

This work was funded by the Cryogenic Propellant Storage and Transfer (CPST) Project under the Office of the Chief Technologist (OCT) at NASA. The authors wish to extend sincere gratitude to the support staff at the Small Multipurpose Research Facility (SMiRF) at NASA Glenn.

\subsection{References}

1'Jaekle, D.E. (1997) "Propellant Management Device Conceptual Design and Analysis: Galleries" AIAA-97-2811.

${ }^{2}$ Jaekle, D.E. (1991) "Propellant Management Device Conceptual Design and Analysis: Vanes" AIAA-91-2172.

${ }^{3}$ Jaekle, D.E. (1993) "Propellant Management Device Conceptual Design and Analysis: Sponges" AIAA-93-1970.

${ }^{4}$ Schweickert, T.F. (1981) "Design of the Aft Propulsion Subsystem for Long Life" JANNAF Propulsion Meeting, New Orleans, May 26 - 28, 1981.

${ }^{5}$ Anglim, D.D. (1981) “Space Shuttle Aft Propulsion Subsystem” AIAA-81-1511.

${ }^{6}$ Fester, D.A., Villars, A.J., and Uney, P.E. (1975) "Surface Tension Propellant Acquisition System Technology for Space Shuttle Reaction Control Tanks" AIAA-75-1196 $11^{\text {th }}$ AIAA/SAE Propulsion Conference, Anaheim, CA, September 29 - October 1, 1975. 
${ }^{7}$ Peterson, R. and Uney, P. (1978) "Development and Qualification of the Space Shuttle Orbiter Reaction Control System Propellant Tank" AIAA-78-1026 $14^{\text {th }}$ Joint Propulsion Conference, Las Vegas, NV, July 25 - 27, 1978.

${ }^{8}$ Anderson, J.E. (1989) "Superfluid Helium Acquisition System Development" Cryogenics 29, $513-516$.

${ }^{9}$ Hartwig, J.W., Chato, D.J., and McQuillen, J.B. (2013) "Performance Gains of Propellant Management Devices for Liquid Hydrogen Depots" AIAA-2013-0368, 51 ${ }^{\text {st }}$ Annual Meeting of the Aerospace Sciences, January 7 - 10, 2012, Grapevine, TX.

${ }^{10}$ Burge, G.W. and Blackmon, J.B. (1973) "Study and Design of Cryogenic Propellant Acquisition Systems - Volume II - Supporting Experimental Program" NAS8-27685 MDAC Report MDC G5038.

${ }^{11}$ Burge, G.W., Blackmon, J.B., and Castle, J.N. (1973) "Design of Propellant Acquisition Systems for Advanced Cryogenic Space Propulsion Systems" AIAA/SAE Propulsion Conference Las Vegas, NV, November 5-7, 1973.

${ }^{12}$ Hartwig, J.W. and Mann, J.A. (2013 I) "A Predictive Bubble Point Pressure Model for Porous Liquid Acquisition Device Screens" Journal of Porous Media (submitted).

${ }^{13}$ Hartwig, J.W., Chato, D.J., McQuillen, J.B., Darr, S.R., and Rame, E. (2013) "A Steady State Pressure Drop Model for Screen Channel Liquid Acquisition Devices" Cryogenics (submitted).

${ }^{14}$ Hartwig, J.W., McQuillen, J.B., and Chato, D.J. (2013) "Screen Channel LAD Bubble Point Tests in Liquid Hydrogen" International Journal of Hydrogen Energy (accepted for publication).

${ }^{15}$ Hartwig, J.W., Mann, J.A., Darr, S.R., and Chato, D.J. (2013) "Parametric Analysis of the Liquid Hydrogen Bubble Point" AICHe Journal (submitted for publication).

${ }^{16}$ Hartwig, J.W., McQuillen, J.B., and Chato, D.J. (2013) "Warm Pressurant Gas Effects on the Liquid Hydrogen Bubble Point" Joint Propulsion Conference, July 15 - 17, 2013, San Jose, CA.

${ }^{17}$ Jurns, J.M and Hartwig, J.W. (2012) "Liquid Oxygen Liquid Acquisition Device Bubble Point Tests with High Pressure LOX at Elevated Temperature" Cryogenics, 52, 283 - 289.

${ }^{18}$ Hartwig, J.W. and McQuillen, J.B. (2011) "Analysis of Screen Channel LAD Bubble Point Tests in Liquid Oxygen at Elevated Temperature" AIAA-2011-3775, 42 $2^{\text {nd }}$ AIAA Thermophysics Conference, June 27 - 30, 2011, Honolulu, HI.

${ }^{19}$ Hartwig, J.W., McQuillen, J.B., and Jurns, J.M. (2013) "Screen Channel LAD Bubble Point Tests in Liquid Oxygen" Journal of Thermophysics and Heat Transfer (accepted for publication).

${ }^{20}$ Hartwig, J.W. and McQuillen, J.B. (2012) "Analysis of Screen Channel LAD Bubble Point Tests in Liquid Methane at Elevated Temperature" AIAA-2012-759, 50 $0^{\text {th }}$ Annual Meeting of the Aerospace Sciences, January 9 - 12, 2012, Nashville, TN.

${ }^{21}$ Hartwig, J.W. and McQuillen, J.B. (2013) "Screen Channel LAD Bubble Point Tests in Liquid Methane" Journal of Thermophysics and Heat Transfer (accepted for publication). 
${ }^{22}$ Hartwig, J.W. and Mann, J.A. (2013 II) "Bubble Point Pressures of Binary Methanol/Water Mixtures" AICHe Journal (accepted for publication).

${ }^{23}$ Hartwig, J.W. and Mann, J.A. (2012) "Room Temperature Bubble Point Tests on Porous Screens: Implications for Cryogenic Liquid Acquisition Devices", 2012 AICHe Annual Meeting, October $28^{\text {th }}-$ November $2^{\text {nd }}, 2012$, Pittsburgh, PA.

${ }^{24}$ Cryogenic Propellant Storage and Transfer (CPST) Technology Demonstration Pre-Phase A Government Point-of-Departure Concept Study, July 27, 2011.

${ }^{25}$ Gravlee, M., Kutter, B., Wollen, M., Rhys, N., and Walls, L. (2009) "CRYOTE (Cryogenic Orbital Testbed) Concept" AIAA-2009-6440, 2009 Space Conference, Pasadena, CA.

${ }^{26}$ Gravlee, M., Vera, C., Wollen, M., McLean, C., and Walls, L. (2010) "Micro-gravity Cryogenic Experiment Opportunity" AIAA-2010-8838, 2010 Space Conference, Anaheim, CA, August 30 - September 2, 2010.

${ }^{27}$ Kutter, B. (2011) Personal correspondence, September 7, 2011.

${ }^{28}$ Thome, J.R. "Wolverine Engineering Databook III: Chapter 10: Boiling Heat Transfer Inside Plain Tubes" available online at www.wlv.com.

${ }^{29}$ Incropera, F.P. and DeWitt, D.P. Fundamentals of Mass and Heat Transfer John Wiley and Sons. New York, NY. 1996.

${ }^{30}$ Paynter, H.L. "Acquisition/Expulsion System for Earth Orbital Propulsion System, Volume III, Cryogenic Test" MCR-73-97, Martin Marietta Corporation, Denver, CO. 1973.

\subsection{Vitae}

Jason Hartwig is a research aerospace engineer in the Propellants and Propulsion branch at the NASA Glenn Research Center in Cleveland, $\mathrm{OH}$ and is the lead technologist for cryogenic propellant transfer. Jason received his B.S. in Physics at John Carroll University, his M.S. in Mechanical Engineering from Case Western Reserve University under the prestigious Case Prime Fellowship, and will receive his $\mathrm{PhD}$ in Aerospace Engineering from Case in 2014. Jason has 9 years of experience in the areas of cryogenic engineering, laser diagnostics, combustion, and propulsion. Jason's area of expertise is in liquid acquisition devices, transfer line and tank chill and fill methods, tank pressurization systems, and multi-layer insulations systems. Jason is a member of CSA, AIAA, AIChE, and SPS.

Dr. David Chato is one of NASA's experts in cryogenic rocket fuel and low gravity fluid management. He holds a Doctorate (2004) from Case Western Reserve University. He also holds both a Bachelors (1980) and a Masters (1985) from the University of Illinois. He currently leads the low gravity fluid management portion of NASA's Cryogenic Propellant Storage and Transfer (CPST) project, as well as serving as Co-Investigator for the Zero Boil-Off Tank (ZBOT) experiment. He has served as Principal Investigator for the NASA Vented Tank Resupply Experiment (1996) and NASA portion of the European Space Agency Sloshsat experiment (2005). Some of his key accomplishments include maturing the no-vent fill technology for fueling spacecraft in low-gravity with liquid cryogen, and advancing the state-of-the-art in 
computer modeling of cryogenic space flight systems. He brings over 25 years of experience to his fields of expertise, including over 40 published papers.

John McQuillen is a senior aerospace engineer in the Fluid Physics and Transport Branch in the Space Processes and Experiments Division. He received a Master of Science in Chemical Engineering from the University of Toledo and has spent his career at the NASA Glenn Research Center. He has spent the majority of his career in the area of reduced gravity two-phase flows, including studies of the governing flow physics, separator design, boiling and thermal management systems. He was the Principal Investigator for the Intravenous Fluid Generation (IV-GEN) project, and is currently active as the project scientist in the Zero Boil Off Tank (ZBOT) Experiment Facility and as a researcher in the Liquid Acquisition Devices in cryogenic tanks. He has authored or co-authored over 75 publications including 18 journal articles. He was the recipient of NASA's Exceptional Achievement Award and the Silver Snoopy Award.

Jerry Vera is an engineer at the NASA Glenn Research Center in Cleveland, $\mathrm{OH}$ in the Fluid Systems Branch of the Engineering Directorate. He has been working at NASA since 2011. He obtained his BSME in 2004 at Rice University in Houston, TX, and is currently a $\mathrm{PhD}$. Candidate in the Department of Mechanical Engineering and Materials Science at Rice University.

Maureen Kudlac works in the Engineering Directorate at NASA Glenn Research Center's Lewis Field in Cleveland Ohio. She is the Fluid Systems Lead for the Cryogenic Propellant Storage and Transfer (CPST) flight experiment. She has over twenty five years of experience as a design, research, and development engineer at NASA Glenn's cryogenic facilities. She holds a BS in Chemical Engineering from the University of Detroit and an MS in Chemical Engineering from Carnegie Mellon University. She is currently a member of the AIAA and CSA.

Frank Quinn is a design engineer with the NASA Glenn Research Center, supporting cryogenic fluid systems research and development. His career spans 26 years working in a variety of diverse projects including in-space propulsion systems, microgravity experiment development and ground based test facilities including aeronautics and cryogenic fluid managements systems. Mr. Quinn holds B.S.M.E and M.S.M.E. degrees from the University of Akron. 